\title{
Urinary Bladder Injury During Colonoscopy Without Colon Perforation
}

\author{
Jung Wook Suh, Jun Won Min, Hwan Namgung, Dong-Guk Park \\ Department of Surgery, Dankook University College of Medicine, Cheonan, Korea
}

We report a case of urinary bladder perforation during colonoscopy. A 67-year-old female, who had undergone a transabdominal hysterectomy for uterine myomas 15 years ago, visited the emergency department with complaint of abdominal pain after a screening colonoscopy. Laparoscopic examination revealed severe adhesion between the sigmoid colon and the urinary bladder. The urinary bladder wall was weakened, and several perforation sites were found. The surgery was converted to a laparotomy. After a thorough examination, we performed primary repair for the perforation sites, followed by an omentopexy.

Keywords: Urinary bladder; Perforation; Colonoscopy

\section{INTRODUCTION}

Because of the increasing incidence of colon cancer, screening colonoscopy is recommended for people above 50 years of age. Therefore, the frequency of performing colonoscopies is rising. Although the complication rate after colonoscopy is relatively low, complications are being increasingly encountered due to the increased number of examinations. Well-known complications of colonoscopy that have been reported include hemorrhage after a polypectomy and colon perforation [1]. Less common complications, such as intra-abdominal hemorrhage and small intestine perforation, can also occur [2-6]. However, urinary bladder injury has rarely been reported. Here, we report a case of urinary bladder perforation during colonoscopy.

\section{CASE REPORT}

A 67-year-old female, who had undergone a transabdominal hys-

Received: November 18, 2016 - Accepted: March 28, 2017

Correspondence to: Hwan Namgung, M.D.

Departments of Surgery, Dankook University College of Medicine, 119

Dandae-ro, Dongnam-gu, Cheonan 31116, Korea

Tel: +82-41-550-3929, Fax: +82-41-565-6167

E-mail: gsnamgung@dankook.ac.kr

(C) 2017 The Korean Society of Coloproctology

This is an open-access article distributed under the terms of the Creative Commons Attribution NonCommercial License (http://creativecommons.org/licenses/by-nc/4.0) which permits unrestricted non-

commercial use, distribution, and reproduction in any medium, provided the original work is properly cited. terectomy for uterine myomas 15 years earlier, but had no history of colon or urinary bladder disease, presented to the emergency department with a complaint of abdominal pain that had lasted for more than 3 hours after a screening colonoscopy. She showed stable vital signs without fever. She complained of mild abdominal pain in the left upper quadrant, periumbilical area, and lower abdomen, all of which began after the colonoscopy. Mild tenderness and rebound tenderness was checked on the left abdomen. Laboratory data showed normal leukocyte count and normal C-reactive protein level. Abdomino-pelvic computed tomography revealed a collapsed rectosigmoid colon with concentric wall thickening and surrounding fatty strands with a scanty amount of fluid collection. Small amounts of ascites existed diffusely along the subphrenic space extending to the pelvic cavity. However, no evidence of intrababdominal free gas was found (Fig. 1).

The patient was initially managed by using conservative treatment. However, she complained of worsening abdominal pain with growing tenderness upon physical examination. In addition, her leukocyte count was elevated. Therefore, we decided to perform an emergency operation. Laparoscopic examination showed that the greater omentum was adhered to the previous incision site and that dark brownish fluid was loculated in the left abdomen. Severe adhesion was found between the sigmoid colon and the urinary bladder. The urinary bladder wall was thin and weakened and had several perforation sites (Fig. 2). After urinary bladder perforation had been diagnosed, the surgery was converted to a laparotomy. The sigmoid colon was dissected from the urinary bladder. The Foley catheter was visible through the urinary blad- 


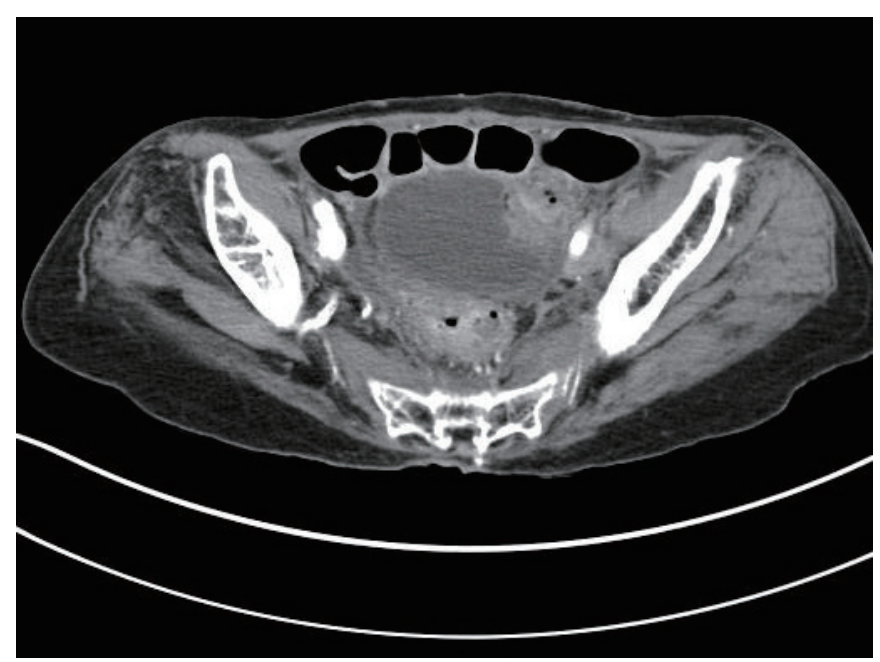

Fig. 1. Abdominal computed tomography scan shows concentric wall thickening of the rectosigmoid colon with surrounding fatty stranding and scanty amount of fluid.

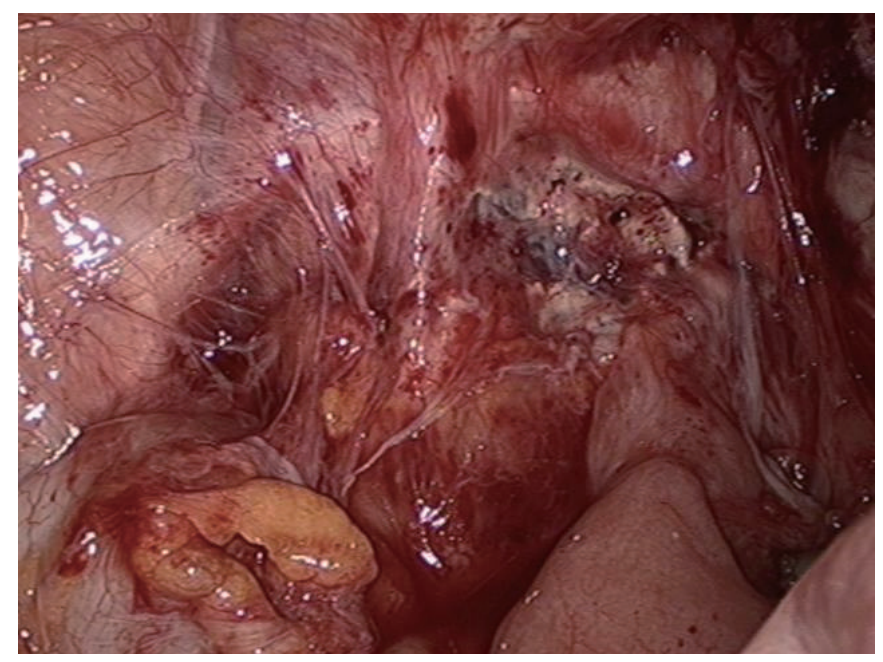

Fig. 2. Laparoscopic findings. Severe adhesion was found between the sigmoid colon and the urinary bladder. The urinary bladder wall in which several perforation sites were found was thin and weakened.

der perforation site (Fig. 3). No evidence of any other injuries, including colon injury, was found in the abdominal cavity. After thorough examination, we performed primary repair of the perforation sites by using one-layer, interrupt suturing with Vicryl 3-0. An omentopexy was added using the greater omentum. After surgery, the Foley catheter was maintained in place for 12 days. On the 12th postoperative day, a cystogram was performed to check for urinary leakage, after which the Foley catheter was removed. After removal of the Foley catheter, the patient was able to urinate smoothly and was discharged in a healthy state.

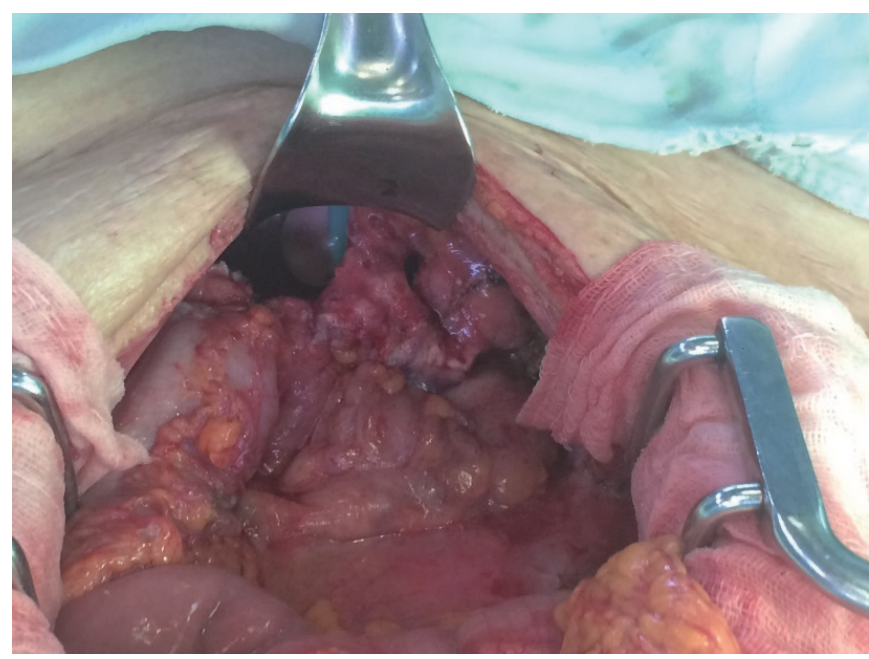

Fig. 3. Operative findings: The Foley catheter was visible through the urinary bladder perforation site after the sigmoid colon had been dissected from the urinary bladder.

\section{DISCUSSION}

The most common complications after colonoscopy are colon perforation and bleeding [1]. When a patient complains of abdominal pain after colonoscopy, colon perforation is the first cause to be considered. The vital signs of the patient should be checked first, followed by a physical examination. A blood test, simple X-ray, and computed tomography are also needed to rule out a perforation. If the patient's condition is stable without a visible pneumoperitoneum on computed tomography, conservative treatment can be considered. If the patient's condition deteriorates, an emergency operation is needed [7].

Less common complications after colonoscopy include small intestine perforation, spleen laceration, and ovary rupture. Patients who have a history of abdominal surgery can suffer from an uncommon organ injury after colonoscopy. Abnormal adhesions of abdominal organs may exist due to previous surgery or other underlying diseases.

In this case, the patient developed abdominal pain 3 hours after screening colonoscopy. Because the symptoms occurred after colonoscopy and no damage to any abdominal organs except the urinary bladder was suspected, the urinary bladder injury was thought to have been caused by the colonoscopy. The mechanism for the urinary bladder injury during colonoscopy can be explained in the following way. The patient's urinary bladder wall was weakened by a previous transabdominal hysterectomy and adhesion existed between the urinary bladder and the sigmoid colon immediately after the loop of the sigmoid colon. The colonoscope can be presumed to have pushed the loop of the sigmoid colon upwards along with the urinary bladder and to have torn the weakened part of the urinary bladder wall. Several attempts to insert the colonoscope is thought to have caused several perfora- 
tions in the weakened urinary bladder wall.

In conclusion, when a patient shows abdominal pain after colonoscopy, a urinary bladder injury is not the first diagnosis to consider. Instead, colon perforation should generally be the initial diagnosis. Therefore, diagnostic tests should focus on colon perforation. Moreover, this case report suggests that colonoscopy can cause injuries to uncommon organs in patients who have a history of abdominal surgery without colon injury.

\section{CONFLICT OF INTEREST}

No potential conflict of interest relevant to this article was reported.

\section{REFERENCES}

1. Dominitz JA, Eisen GM, Baron TH, Goldstein JL, Hirota WK, Jacobson BC, et al. Complications of colonoscopy. Gastrointest Endosc 2003;57:441-5.
2. Singla S, Keller D, Thirunavukarasu P, Tamandl D, Gupta S, Gaughan J, et al. Splenic injury during colonoscopy: a complication that warrants urgent attention. J Gastrointest Surg 2012;16: 1225-34.

3. Tagg W, Woods S, Razdan R, Gagliardi J, Steenbergen P. Hemoperitoneum after colonoscopy. Endoscopy 2008;40 Suppl 2:E1367.

4. Desai B. Splenic laceration following routine colonoscopy. South Med J 2010;103:1181-3.

5. Lambert A, Nguyen SQ, Byrn JC, Fishman EW, Shen HY. Smallbowel perforation after colonoscopy. Gastrointest Endosc 2007; 65:352-3.

6. Pasumarthya L, Srourb J, Johnsonc D. Jejunal perforation following screening colonoscopy Case Rep Gastroenterol 2008;2:18790.

7. Shin DK, Shin SY, Park CY, Jin SM, Cho YH, Kim WH, et al. Optimal methods for the management of iatrogenic colonoscopic perforation. Clin Endosc 2016;49:282-8. 